
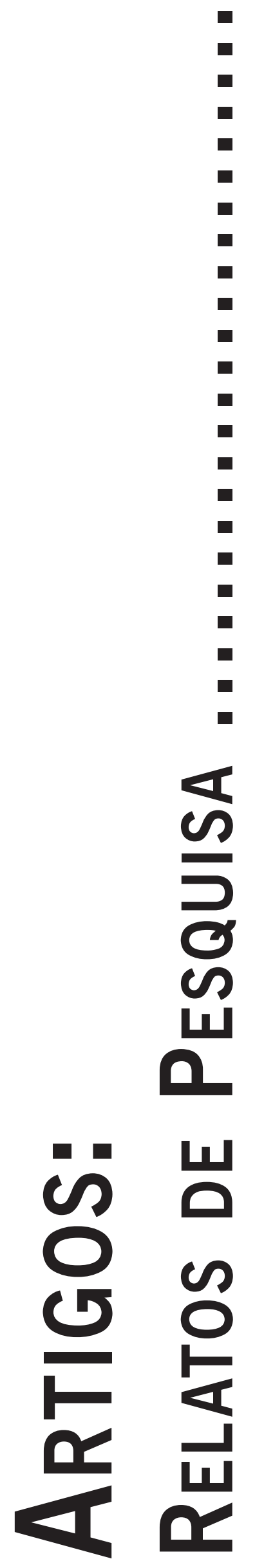


\title{
MULHERES TRANSPLANTADAS RENAIS: UM OLHAR FENOMENOLÓGICO EXISTENCIAL PARA A EXPERIÊNCIA DA GESTAÇÃO
}

\author{
Women Transplanted Kidney: the Experience of Pregnancy in Focus
}

Mujeres Riñón Trasplantado: la Experiéncia del Embarazo en Foco

Viviane Rodrigues de Figueredo Azevedo Amaral

Telma Costa de Avelar

Suely EMILIA DE BARRos SANTOS

\begin{abstract}
Resumo: Atualmente no Brasil a Insuficiência Renal Crônica (IRC) é considerada um problema de Saúde Pública, pela elevada prevalência, incidência e risco de mortalidade. A IRC demanda um tratamento de elevado custo e difícil prognóstico. Nesse contexto, o presente trabalho faz um recorte acerca do fenômeno da gestação no pós-transplante. Seu objetivo é compreender como as mulheres transplantadas renais experienciam a gestação, considerando que tanto a gravidez quanto o acometimento renal trazem mudanças significativas à sua vida. Para tanto, utilizou-se uma abordagem qualitativa, adotando-se a fenomenologia existencial como referência metodológica. Como participantes, duas mulheres concederam entrevistas abertas; suas narrativas foram analisadas tendo como referencial o método da Analítica de Sentido, proposta por Dulce Critelli. Nas narrativas apreendeu-se que a angústia em sua dimensão ontológica manifestou-se onticamente pelo medo/temor, referente à perda do enxerto e do próprio bebê esperado, além da interdição à amamentação enquanto fator de risco psicoemocional. O cuidado de si e do outro atravessou todos os acontecimentos numa pró-cura - para cuidar de existir no mundo-com-outros. A intervenção psicológica à gestante transplantada renal e sua família revelou-se primordial para o acontecer de uma atenção, orientada pelos princípios éticos.
\end{abstract}

Palavras-chave: Transplante renal; Gestação; Psicologia; Fenomenologia Existencial.

Abstract: Currently in Brazil Chronic Renal Failure (CRF) is considered a public health problem by its high prevalence, incidence and mortality risk, generating a costly and difficult prognosis. In this context, the present study makes a bridge between the pregnancy phenomenon in post-transplant. It's goal is to understand how the kidney transplanted women experience pregnancy, considering that both pregnancy and renal involvement bring significant changes to their life. Therefore, we used a qualitative approach, adopting the existential phenomenology as a theoretical and methodological support. As participants, two women gave open interviews; their narratives were analyzed using as reference the direction of Analytical method proposed by Dulce Critelli. Throughout the testimonials, it is made understood that the anguish, in its ontological dimension, had taken place ontically beacause of Fear/Scare from the graft loss and the loss of their own expected child, beside the ban on breastfeeding as psychoemotional risk fator. The caring towards oneself and towards others went through all events in a pro-healing process - in order to take care of existing in the world-whit-others. The psychological care to kidney transplanted pregnant women and their families proved to be essential matter on the happening of attention guided by ethical príncipes.

Keywords: Kidney Transplantation; Pregnancy; Psichology, Existential Phenomenology.

Resumen: Actualmente en Brasil la Insuficiencia Renal Crónica (IRC) es considera un problema de salud pública por la elevada prevalencia, incidencia y riesgo de mortalidade. La IRC demanda un tratamiento de coste elevado y difícil pronóstico. En el contexto, ese trabajo hace un inciso sobre el fenómeno del embarazo en el post-trasplante, su objetivo es comprender como las mujeres trasplantadas renales viven la gestación, teniendo en cuenta que tanto la gestación como el acometido renal conllevan cambios significativos en su vida. Para tal, se utilizó un abordaje cualitativo, adoptando la fenomenología existencial como soporte teórico y metodológico. Como participantes, dos mujeres concedieron entrevistas abiertas; sus relatos fueron analizados teniendo como referencia el método de la Analítica del Sentido, propuesto por Dulce Critelli. De los relatos se deprendió que la angustia, en su dimensión ontólogica, se ha creado ónticamente por el miedo/temor referente à la perdida del injerto y del próprio bebé esperado, además la interdicción del amamantamiento como fator de riesgo psicoemocional. El cuidado de uno e del otro ha passado a través de todos los eventos en una pró-cura - para cuidar de existir en el mundo-con-otros. La intervención psicológica a las mujeres transplantadas renales embarazadas y sus famílias se ha mostrado de importância fundamental para el acontecer de una atención, guiadas por los princípios éticos.

Palabras-clave: Trasplante de Riñón; Gestación; Psicología; Fenomenlogía Existencial. 


\section{Introdução}

O presente artigo é fruto de uma pesquisa científica que teve como objetivo compreender como as mulheres transplantadas renais experienciam a gestação. Buscou-se ainda apreender o fenômeno da gestação no contexto do transplante renal, promovendo uma discussão à luz da fenomenologia existencial.

$\mathrm{O}$ adoecimento pode trazer mudanças radicais para a vida da pessoa. As limitações causadas pela doença resultam em rupturas e perdas em diversos contextos da vida. O corpo, que antes mostrava a presença de uma saúde mais fortalecida, com a doença, passa a expressar-se de outro modo, causando dores, perdas, angústias. Em relação ao adoecimento, Quintas (2013), relata que, do ponto de vista existencial, essa pode ser a experiência que mais afeta o ser humano, por apontar a sua finitude. $\mathrm{Na}$ experiência de adoecimento causado pela Insuficiência Renal Crônica (IRC) não é diferente. O doente renal crônico encontra-se frequentemente vulnerável e fragilizado por suas perdas, que vão além da perda da função renal, tais como: perda de uma parte da autonomia, liberdade, energia cotidiana, atividades laborais, vínculos sociais, tendo que enfrentar, ainda, as limitações hídricas e restrições alimentares (Freitas \& Cosmo, 2010).

Atualmente, no Brasil, a IRC é considerada um problema de Saúde Pública. Sua incidência e prevalência estão aumentando, com difícil prognóstico e elevado custo de tratamento (Sesso, Lopes, Thomé, Lugon, Watanabe \& Santos, 2012). A IRC é uma doença grave que se caracteriza pela perda lenta e progressiva da função dos rins, e classifica-se em estágios que vão do primeiro ao quinto. No último estágio, a doença pode agravar até levar à morte, e a sobrevida pode ser garantida por intermédio da terapia renal substitutiva (TRS) - hemodiálise, diálise peritoneal e transplante renal (Tavares, 2011). Segundo o Manual de Transplante Renal (ABTO, 2014a), o transplante renal, modalidade da TRS na qual nos deteremos neste estudo, consiste na transferência de um rim de um humano para o outro com o objetivo de compensar a função renal perdida. O transplante renal proporciona melhor condição de saúde, e, consequentemente, melhor qualidade de vida. No Brasil, apenas 5\% dos pacientes no quinto estágio da IRC são submetidos ao transplante renal. Vale ressaltar que, dos inscritos na fila de transplante, 19\% realizam o procedimento. Entre janeiro e setembro de 2014, houve 4.221 transplantes de rins no Brasil, entre esses 218 foram realizados em Pernambuco (ABTO, 2014b).

Na população acometida pela IRC, encontramos mulheres em idade fértil com a capacidade reprodutiva diminuída por causa da doença renal. Ao serem transplantadas, elas passam a ter mais chances de engravidar, pois as funções renal e endócrina são rapidamente retomadas, resultando em uma maior fertilidade. Silva, Cardoso, Sá, Kruger e Oliveira (2014) consideram que, apesar da gravidez no contexto de IRC ser de alto risco, o transplante renal não é uma contraindicação para a gestação, porém o bom andamento dessa, depende de um rigoroso planejamento e acompanhamento multiprofissional.

Na medida em que vem a colaborar com o diálogo científico acerca da experiência da gestação na mulher transplantada renal, este estudo torna-se relevante, por ampliar a literatura na área, que é escassa, conforme revelou a pesquisa literária realizada na base de Artigos Científicos do Scientific Electronic Library Online (SciELO), Portal de teses e dissertações da Coordenação de Aperfeiçoamento de Pessoal de Nível Superior (CAPES), LILACS, IBECS e MEDLINE.

\section{Transplante Renal: uma revolução interna}

O transplante renal é um grande avanço da medicina moderna. Hoje a Política Nacional de Transplantes de Órgãos e Tecidos está fundamentada na Legislação (Lei no 9.434/1997 (Brasil, 1997) e Lei no 10.211/2001 (Brasil, 2001), apresentando como diretrizes a gratuidade da doação, a beneficência em relação aos receptores e não maleficência em relação aos doadores vivos. Toda a Política de Transplante está em sintonia com as Leis $n^{0}$ 8.080/1990 (Brasil, 1990a) e nº 8.142/1990 (Brasil, 1990b), que regem o funcionamento do Sistema Único de Saúde (SUS). Vale ressaltar que mais de 95\% dos transplantes são realizados no SUS (Medina-Pestana, Galante, Tedesco-Silva Jr., Harada, Garcia, Abbud-Filho, Campos \& Sabbaga, 2011).

Após o transplante renal, vem a interrupção do tratamento dialítico - diálise peritoneal ou hemodiálise, o que favorece um contexto com maiores possibilidades de retorno à vida profissional e social. Esses são fatores que apontam para uma melhor qualidade de vida proporcionados pelo processo de transplante renal (Ravagnani, Domingos \& Miyazki, 2007). Esse transplante não corresponde à cura do problema renal, entretanto costuma melhorar consideravelmente a qualidade de vida da pessoa transplantada, podendo contar com uma maior autonomia, possibilitando-lhe a retomada de projetos que foram adiados ou impossibilitados pelas limitações causadas pela IRC.

Tanto o doente renal crônico, quanto a equipe de saúde costumam ver o transplante como uma experiência positiva. No entanto, é de extrema necessidade ressaltar que o transplantado não está livre de vivenciar momentos de crise psicoemocional, social e fisiológica. Conforme Quérin, Clermont, Dupre-Goudable e Dalmon (2011), no percurso do transplantado existem sucessivos lutos. O primeiro é pela perda da sua própria função renal - de uma saúde antes conhecida; seguido de certa perda da imagem de si mesmo, provocando um estado de vulnerabilidade. Além disso, ele conhecerá algumas mudanças, tais como: o tratamento com imunossupressores, a nova equipe de saúde, uma nova higiene de vida. 
Rossi, Deus e Figueiredo (2011) definem o transplante não como um acontecimento em si, marcado pela cirurgia, mas enquanto processo, pois ele não inicia ou finaliza com a cirurgia. O paciente antes de ser transplantado segue uma rotina de consultas e exames e, após o ato cirúrgico, adere a um esquema de dieta e medicamentos rigorosos. Bohachick et al. (1992) afirmam que o transplante é um processo marcado por uma série de etapas preenchidas por estressores significativos e o primeiro deles é o reconhecimento da doença enquanto ameaçadora da vida. Os problemas bio-psico-sociais são profundos antes e depois da cirurgia de transplante. É o que precede e sucede o ato cirúrgico que deve ser o foco permanente do transplantado, sua família e equipe de saúde no processo de cuidado.

O humano transplantado costuma expressar o sentimento de renascimento ao falar do transplante, apesar de saber que este não corresponde a uma cura e que surgirão dificuldades, mudanças e crises que lhe são peculiares. O transplante renal pode ser entendido como uma revolução, não só para a ciência, e mais especificamente para a nefrologia, mas também como uma revolução interna para aquele que foi acometido pela IRC. Revolução no sentido de que, a partir do transplante, poderá haver transformações profundas e intensas na sua vida. Assim sendo, para melhor enfrentamento do processo de transplante, faz-se necessária a articulação do cuidado do próprio transplantado, da sua família e da equipe de saúde multiprofissional interdisciplinar.

\section{Gestação em mulheres transplantadas: uma segunda revolução interna}

Maldonado (2002) enfatiza que algumas mulheres vivenciam a gestação como um período de crise, outras conseguem vivê-la de forma mais serena em meio às diversas mudanças. Se o transplante renal pode ser considerado, em diferentes contextos, uma revolução, para a mulher transplantada que engravida, a gestação pode representar uma grande metamorfose permeada de mudanças e reorganizações fisiológicas, sociais, psicológicas, familiares e econômicas, que anuncia uma segunda revolução interna.

De acordo com Silva et al. (2014), durante muito tempo, a orientação médica para a gravidez associada à nefropatia era a sua interrupção. Em 1960, as mulheres pós-transplantadas seguiam com a gestação apenas por razões emocionais ou religiosas. Ainda no início dos anos 70 , era frequente que os bebês de mulheres com IRC nascessem em condições delicadas, sendo em sua maioria, natimortos. Porém, em 1960, foi descrito o primeiro caso de gestação bem-sucedida pós-transplante renal. Hoje se sabe que as complicações maternas mais comuns nesse tipo de gravidez são: maior probabilidade de cesariana, anemia, diabetes gestacional, infecções, rejeição aguda do enxerto, pré-eclampsia; e, entre as complicações fetais, podemos encontrar crescimento intrauterino restrito, parto pré-termo, infecções, anemia, malformações, insuficiência suprarrenal e anormalidades cromossômica. Porém, o bom andamento dessa gestação não se deve apenas aos fatores fisiológicos, mas também aos psicológicos e sociais.

A mulher transplantada renal grávida deve ser acompanhada por um obstetra e um nefrologista. Se o acompanhamento não for adequado, a função do enxerto pode ficar comprometida, assim como a vida da paciente e o desenvolvimento do feto (Silva et al., 2014). Essa gravidez é considerada de alto risco tanto para a mãe quanto para o feto, por ser "aquela na qual a vida ou a saúde da mãe e/ou do feto e/ou do recém-nascido têm maiores chances de serem atingidas que as da média da população considerada" (Brasil, 2012, p. 11). Para estas mulheres, em comparação com a população geral, existe um maior risco de a criança nascer prematura - entre a $20^{\mathrm{a}}$ e $37^{\mathrm{a}}$ semana, ou com baixo peso - menos de $2.000 \mathrm{~g}$. Vale ressaltar que essas crianças geralmente não apresentam atraso no desenvolvimento (Panaye, Jolivot, Lemoine, Guebre-Egziabher, Doret, Morelon \& Juillard, 2014).

Segundo Silva et al. (2014), a idade das gestantes transplantadas varia de 20 a 36 anos, a gestação geralmente chega as 33 semanas. A deterioração da função renal aparece em 5,5\% dos casos. Os nefrologistas concordam que é recomendável esperar dois anos após o ato cirúrgico do transplante renal para engravidar, tendo em vista as doses mais elevadas dos imunossupressores e o risco de rejeição do órgão recebido. Esses autores citaram alguns critérios para avaliar a indicação ou não da gravidez em transplantadas renal: ter boa saúde geral, função estável do enxerto, não haver recentes episódios de rejeição aguda e nenhuma evidência de rejeição no momento, ausência de proteinúria ou mínima de $<5 \mathrm{~g} /$ dia e pressão arterial normal. A gestação em contexto de IRC, além de representar riscos orgânicos, objetivos e mensuráveis, pode ser habitada por ansiedade, angústia, ambivalência, medo, baixa autoestima, sentimento de incompetência, dificuldade na vinculação com o bebê, sentimento de ser diferente das demais, o que possivelmente será reforçado pelo rótulo "de alto risco" (Caldas, Silva, Boing, Crepaldi \& Custódio, 2013). Esses são fatores de risco psicoemocional que a gestante transplantada pode enfrentar ao longo da sua gestação.

Sendo assim, fica claro que a mulher que engravida após um transplante renal deve ser acompanhada por uma equipe formada por profissionais de diferentes áreas, trabalhando de forma planejada e articulada para que o cuidado oferecido seja o mais acolhedor possível (Brasil, 2012). 


\section{Procedimentos metodológicos}

Este artigo é fruto de uma pesquisa qualitativa, numa perspectiva fenomenológica existencial. A pesquisa qualitativa segundo Minayo (2002), "trabalha com o universo de significados, motivos, aspirações, crenças, valores e atitudes, o que corresponde a um espaço mais profundo das relações, dos processos e dos fenômenos que não podem ser reduzidos à operacionalização de variáveis" (p. 21-22). A palavra fenômeno pode ter vários significados. Heidegger (1927/2002) compreende o fenômeno como o que se revela, que se faz ver ou que vem à luz. Critelli (2006) menciona o fenômeno ao mesmo tempo que traz a noção de ente:

Ente é tudo o que é, o que tem uma manifestação (uma pedra, uma emoção, idéia...). E manifestação é uma exposição, um mostrar-se do ente, um trazer-se à luz para um olhar [...] Fenômeno (de onde a fenomenologia também retira seu nome) é o ente mostrando-se. (p. 54, parênteses da autora)

Nessa direção, olhamos para modos possíveis do fenômeno da gestação se apresentar em mulheres transplantadas renais. Para tanto, neste trabalho, foram realizadas duas entrevistas abertas de forma individual com duas mulheres colaboradoras, totalizando quatro entrevistas. Partiu-se da seguinte inquietação da pesquisadora, que se fez questão norteadora para a direção da pesquisa: "Como é a experiência da gestação para as mulheres que foram submetidas a um transplante renal?". Entretanto, na entrevista, foi lançada a seguinte questão disparadora para as mulheres participantes: "Como foi a sua experiência de gestação após o transplante?". Trabalhamos com uma amostra intencional, a qual, segundo Thiollent (1986), se refere a "um pequeno número de pessoas que são escolhidas intencionalmente em função da relevância que elas apresentam em relação a um determinado assunto" (p. 62). As duas mulheres entrevistadas foram selecionadas pelos seguintes critérios: ambas eram adultas, estiveram grávidas após um transplante renal e eram acompanhadas pelo Ambulatório de Nefrologia do Hospital das Clínicas da Universidade Federal de Pernambuco (HC-UFPE), local de realização da pesquisa.

Para analisar as narrativas, o método escolhido foi o da "Analítica do Sentido", proposto por Dulce Critelli (1996), que possibilita o acompanhar da manifestação do sentido. Neste artigo compreende-se sentido como:

A direção, o rumo para onde se vai, estando assim atrelado ao destinar-se [...] o sentido é uma armação sem a qual o mundo não se arruma, organiza; configurando-se somente na direção humana, todos os demais entes são carentes de sentido. Fenomenológica existencialmente, a pergunta pelo ser não se dirige ao que é, porém ao sentido de ser. (Almeida, 2005, p. 213)
A Analítica do Sentido tem cinco movimentos, segundo Critelli (1996):

a) Desvelamento - Modo como o fenômeno que estava ocultado se desvela. É o momento o da afetabilidade;

b) Revelação - Anuncia, pela compreensibilidade, o aparecimento do fenômeno;

c) Testemunho - É o momento de compartilhar com outros, da comunicabilidade do que foi revelado;

d) Veracização - O fenômeno não se mostra como uma verdade, mas pode ser veracizado a partir das referências, de outros olhares;

e) Autenticação - No compartilhar com outros, na publicização, a pesquisa pode ser autenticada.

Esclarecemos que, como destaca a referida autora, esses movimentos não se apresentam de forma linear, mas sim pela simultaneidade. Assim, não se mostram como etapas a serem seguidas, mas como um constante ir e vir por entre os referidos movimentos. Desta forma, a análise apresentada a seguir não segue fases ou passos, mas um permanente movimento para compreensão de sentido.

\section{Possibilidades compreensivas da experiência da gestação da mulher transplantada renal}

Este estudo teve a colaboração de duas mulheres, que por meio da narrativa, contaram suas experiências acerca da gestação após o transplante renal. A primeira narradora-colaboradora, Eliana, 43 anos, tem dois filhos, transplantada em 2005. Sua primeira gestação aconteceu dois anos após o transplante e a segunda cinco anos após. A segunda narradora-colaboradora, Maria Eduarda, 44 anos, transplantada há 19 anos, tem uma filha, engravidou 07 anos após o transplante. Compreendendo que em mulheres com IRC os riscos para uma gestação são constantes, como assinalam Brasil (2012) e Panaye et al. (2014), podemos entender que, apesar das gestações das narradoras-colaboradoras terem início dois anos após o ato cirúrgico do transplante, ou seja, em um tempo recomendado pelos nefrologistas e obstetras, a gestação continua sendo de risco, pois o que constitui o caráter de risco, nesse contexto, não é a quantidade de anos que se passaram após a cirurgia do transplante, mas o fato da mulher ser transplantada renal. Além disso, é preciso ficar atento, pois "o que importa é o tempo vivido, biografado nas dobras do vivido (o kairós) e não o tempo físico, controlado medido, previsto (o chronós)" (Santos, 2005, p. 91, grifos da autora). O kairós não segue uma linearidade, nem pode ser medido ou pré-determinado. É o tempo que vai se deslocando e modificando ao se transitar pela experiência do viver por entre a trama de sentido. Mas há uma preocupação da equipe de saúde com o tempo chronós, como podemos ver na narrativa de Eliana: 
Eliana - O médico disse... "olha... a gravidez a gente não aconselha não... só a partir de dois anos de transplante!”... E foi justamente nesta época que eu engravidei! [...] Fiz todos os tipos de exames! Qualquer coisa que eu sentia vinha aqui... qualquer dor de cabeça eu vinha aqui!

A maneira como a mulher vive a gestação após um transplante renal é única, pois cada uma dará seu próprio sentido ao caminhar enquanto gestante submetida ao transplante renal. A singularidade da experiência é construída por intermédio da sua história de vida, do apoio familiar e social que recebe, da sua condição fisiológica, do acompanhamento que teve junto à equipe de saúde, dos seus projetos de vida. Apesar da experiência da gestação após o transplante renal ser singular, podemos encontrar pontos em comum nas narrativas de Eliana e Maria Eduarda, como por exemplo, a presença do cuidado, tanto de si quanto do outro, no contexto da gestação e da IRC. Esse destaque para o cuidado leva-nos ao pensamento de Heidegger (1927/2002) ao compreender o cuidado como condição originária do ser-aí. Entretanto, assinalamos que, no decorrer dessa análise, apresentaremos os modos ônticos do cuidado se manifestar, neste estudo.

Heidegger (2002) faz um desdobramento do cuidado (Sorge) em ocupação (Bersogen) com os entes que estão as nossas mãos, e em preocupação, solicitude (Fürsogen) para com os outros. Segundo Loparic (2013), Sorge é "o ter-que-ser que tem o sentido de ter que se responsabilizar ontologicamente e onticamente por si mesmo, pelos outros seres humanos e pelo mundo" (p. 44-45). Pode-se compreender que pela ocupação há um cuidado superprotetor, que desresponsabiliza o humano de sua tarefa de cuidar do seu poder-ser, enquanto que, a preocupação, como diz Duarte (2013), “o pôr-se diante do outro não suprimiria nem supriria suas ocupações e necessidades, mas cuidaria do outro ao restituir-lhe ao próprio cuidado de si” (p. 67). Ou nas palavras de Loparic (1995), a solicitude

[...] não se ocupa das necessidades concretas do outro, mas direta e imediatamente do seu existir enquanto livre de todas as normas. [...] Cuidar verdadeiramente do outro não significa, portanto, nem racionalmente normatizá-lo, nem socializá-lo. Tampouco quer dizer inserir o outro numa história coletiva. O futuro aberto pelo cuidado não promete um final salutar, apenas possibilita o agir na situação presente. (p. 66-67)

Pode-se compreender que o cuidado vai além de um ato pontual, ou uma virtude, mas é um modo de ser-no-mundo. $\mathrm{O}$ cuidado antecede as relações do homem com todas as coisas. Ou como afirma Santos (2016), “[...] o cuidado se mostra como condição própria de o homem existir. O destinar-se a estar cuidando de existir carrega uma tarefa primordial de responsabilizar-se por si mesmo, pelos outros e pelo mundo" (p. 183, grifos da autora).
Essa forma de pensar o cuidado vai de acordo com o que traz Potes, Pelaez e Escobar (2011): “o cuidado se encontra na raiz primeira do ser humano, tudo o que fará irá sempre acompanhado do cuidado e impregnado de cuidado. O cuidado é uma dimensão ontológica, originária” (p. 134). Assim, o ser humano é cuidado. Entretanto, onticamente, existem modos desse cuidado se manifestar e o que, muitas vezes, poderia ser tomado como ocupação, como as consultas médicas, o aguardar o tempo "adequado" para engravidar, pode ser acompanhado de preocupação no cuidar de si e do outro, como expressividade ôntica da condição humana de ser no mundo como cuidado:

Maria Eduarda - Eu ia certinho para as minhas consultas! Fiquei sendo acompanhada pelo nefrologista e pelo obstetra!

Eliana - O doutor da vascular disse: "não era pra você ter engravidado!". Meu médico que fez meu transplante, também disse: "graças a Deus que deu certo, graças a Deus, mas poderia não ter dado. Você poderia ter evitado a segunda gravidez... mas...” [...] As enfermeiras comentavam que por eu ser transplantada podia prejudicar meu rim transplantado.

A partir do apropriar-se do cuidado de si e do outro, foi revelado, também, na narrativa de Maria Eduarda, o medo enquanto tonalidade afetiva que a acompanhou durante toda a gestação. A disposição afetiva é um existencial, que onticamente diz respeito aos humores cotidianos. Para Heidegger (1927/2002), O humor revela 'como alguém está e se torna’. (p. 188). Compreendemos que o medo diante do vivido e do devir, já se desvela nas expectativas de sua história pós-parto, entremeado pela possibilidade de lidar com sua própria finitude e/ou a daquele que está gestando. Como a disposição "se manifesta numa tonalidade afetiva, constituindo-se como um modo de ser da abertura do ser-no-mundo" (Santos, 2016, p. 159), o medo se revela como um modo possível da narradora-colaboradora ser tocada pelo que experiencia com-os-outros no mundo:

Maria Eduarda - O medo nunca ficava longe de mim... a gestação toda! [...] O medo de perder o transplante... o medo da criança ter problema por causa do uso exagerado de remédios! Quer dizer... o uso necessário! Eu tomo duzentos e vinte comprimidos por mês! Vem um monte de coisa na sua cabeça... se a criança vai nascer normal... se vai nascer e vai sobreviver devido a tomada de muitos medicamentos![...] Quando eu fiz meu pré-natal e tive a minha filha... eu quis fazer a laqueadura de trompas! Mas o meu nefrologista não liberou! Eu não queria me arriscar novamente! Eu achava que por eu ter uma filha só... já bastava! Porque eu tenho uma filha para criar... e eu não queria que na próxima gestação... eu passasse por tudo isso de novo! 
Será que o medo revelado a faz apropriar-se do cuidado de si e do outro? Será a busca da laqueadura de trompas um modo de manifestação do cuidado de si e do outro? Mas, apesar de Maria Eduarda pensar na possibilidade da laqueadura considerando não só a experiência da gestação, mas, também o devir, já olhando para a pós-gestação, o seu depoimento não encontrou ressonância na "ordem/ decisão médica”, e o procedimento não foi realizado. Entretanto, a atitude em "ser-cuidado" revela sua responsabilidade consigo e com a filha que iria nascer desvelada de forma significativa no seu pedido/escolha pela laqueadura de trompas. Por ter conhecido diversos riscos antes e após a gravidez, ela não queria arriscar outra gestação. A experiência de Maria Eduarda nos remete a Caldas et al. (2013), quando afirmam: "Na gestação de alto risco [...] há o acréscimo de diversas outras emoções vinculadas à condição clínica. $\mathrm{O}$ fator de risco implica medo real sobre si mesma e em relação ao próprio filho" (p. 71).

O medo expressado não é fantasmático e não faz parte apenas da experiência da gestante transplantada renal. A sua família também vivencia o sentimento de medo durante a gestação. Para a paciente e sua família, a IRC e seu tratamento representam uma crise vital significativa, elas não costumam estar preparadas para as mudanças físicas, para os períodos mais instáveis e para a incerteza do futuro. Não só a paciente, mas também a família conhece perdas diversas durante a história do adoecimento (Bruscato, 2004). A gestação no contexto de IRC gera angústia, dúvidas e receios à família, que não espera e nem cobra do casal uma gestação, pois acredita que esta pode colocar em risco a saúde da mulher transplantada. Antes de a gestação acontecer, parece não existir lugar para ela no seio familiar. A família, então, parece não desejar a gestação do casal, não projetar, não esperar. Ao receber a notícia da gravidez, a preocupação e a desaprovação dos outros, muitas vezes, podem ser compreendidos como um modo do cuidado se manifestar?

Eliana - A minha mãe não queria que eu engravidasse! Ela disse... "você tá louca? Isso não podia acontecer! Você é transplantada!” Ela não queria nem acreditar que eu estava grávida... ela não queria acreditar! Porque ela sabe do meu sofrimento! Depois do transplante eu peguei um tipo de bactéria [...] Eu passei quase dois meses aqui internada! Nessa época eu sofri... sofri muito. Eu não tinha mais nem veia para furar no meu braço. Então ela ficou com medo disso aí! Sabendo do meu sofrimento... acompanhando todo o meu sofrimento e não queria mais que eu passasse por isso! Então ela ficou assim... não queria que eu engravidasse... Dizia que depois eu adotava uma criança... já que eu queria tanto! [...] A gente escondeu a segunda gravidez... só vim dizer quando estava com uns três meses! A minha irmã soube... mas não fui eu que contei... foi o meu esposo! Aí eu recebi uma bronca dela... "Você engravidou de novo? Você não deveria ter feito isso... deveria ter evitado!” Nem a minha mãe sabia! Ela disse... "não era pra ter acontecido... você já tem um menino... pra quê você foi engravidar de novo?” A família fica preocupada!

Podemos ver nessa narrativa que a falta de informação da família sobre a gestação em mulheres transplantadas renais parece interferir no modo como os familiares lidam com o fenômeno da gravidez. Essa se transforma no início em um "drama familiar". Entretanto, num olhar pela fenomenologia existencial, podemos compreender que a atitude familiar de receio/temor, de aparente não aceitação, reveste-se de uma pré-ocupação com o modo da gestante viver sua existência, desvelada na disposição de espantar-se com a confirmação de uma gestação de risco. Como sinaliza Rodrigues (2006),

[...] a disposição do temor, por se dar na impropriedade, é muito mais comumente reconhecida do que a angústia, embora seja esta que, através do desvio da de-cadência, torne possível o temor. O que se teme é sempre um ente que vem ao encontro dentro do mundo. De forma diversa da angústia, na qual o pelo que se angustia é indeterminado, no temor, o que se teme possui o caráter de um determinado dano que ameaça o ser. (p. 61)

Além disso, podemos pensar que a vivência dessa pré-ocupção, revela a condição humana de ser-no-mundocom-outros, pois o "O mundo da pre-sença é mundo compartilhado. O ser-em é ser-com os outros. O ser-em-si intramundano destes outros é co-presença” (Heidegger, 1927/2002): (p. 170). Nessa situação, fica claro que não devemos acompanhar apenas a mulher grávida, mas a família grávida:

Maria Eduarda - Todo mundo ficou preocupado! A primeira pergunta... "e você pode ter filho? Como é que vai ser a sua vida? Você vai perder o transplante? A criança vai nascer normal?” A minha família aceitou... mas foi aquela coisa... "meu Deus!!... ela é louca!... não poderia ter acontecido!...ela deveria ter evitado!” Até porque ninguém tinha essa experiência... nem eu conhecia ninguém... nem tinha ninguém na família assim! Ela ficou assustada!

Eliana - Porque o povo fazia medo, né? Transplantada... [... "mas Eliana, você transplantada... engravidar de novo?” Isso fazia medo, né?

Será que a ameaça é algo concreto e determinado como poder ou não poder engravidar? Pensamos na possibilidade do humano angustiar-se por seu próprio ser-no-mundo-com-outros, por seu próprio poder-ser-no-mundo-com-outros. Na realidade o homem foge da estranheza de deparar-se com o ser projeto, mesmo que situado nu- 
ma tradição, numa cultura. Angustia-se com o responsabilizar-se em encaminhar sua destinação. Vale apontar que Heidegger (1927/2002) pensa a angústia como fenômeno existencial da finitude humana. Assim, a angústia reveste-se de uma marca eminentemente humana e, desse modo, só o homem se angustia.

Por outro lado, considerando o que foi revelado nas narrativas citadas, é relevante que a mulher gestante submetida anteriormente ao transplante, juntamente com sua família, sejam acompanhadas por uma equipe de saúde multiprofissional de enfoque interdisciplinar. Essa equipe pode orientar e apoiar a gestante e sua família, acolhendo suas dúvidas, sentimentos, experiência do adoecimento e da gravidez, à luz da sua história de vida. A gestante e sua família devem ser mantidas informadas e instruídas quanto aos comportamentos e atitudes que precisam ter no período gravídico para obter maior bem-estar (Brasil, 2012). A família deve ser preparada para fornecer um suporte adequado a esta gestante e para isso, precisa também de cuidados. No acompanhamento de uma gravidez de alto risco, como é o caso da gravidez após transplante renal, a equipe de saúde precisa atuar com objetivo de diminuir os riscos aos quais a gestante, o feto e a família estão expostos. Ela precisa estar preparada e possibilitar um espaço para abordar os inúmeros fatores que surgem e que podem afetar negativamente o processo da gestação.

A interdição à amamentação aparece como um fator de risco psicoemocional de grande relevância na experiência da gestação das narradoras-colaboradoras. Durante a gestação, ambas as entrevistadas foram informadas pela equipe de saúde sobre a contraindicação da amamentação em mulheres transplantadas renais, tendo como justificativa a exposição do recém-nascido aos imunossupressores, medicamentos aos quais ele já esteve submetido durante a fase intrauterina. Porém, não existe um consenso sobre essa questão. Segundo Ribeiro (2010), alguns relatos de casos mais atuais defendem que o uso de determinados imunossupressores é compatível com a amamentação, alegando/demonstrando/indicando que os bebês crescem sem alterações no desenvolvimento. Contudo, é preciso considerar com atenção que drogas estão sendo usadas e como se dá as interações destas.

As narradoras-colaboradoras foram informadas sobre a impossibilidade da amamentação, mas a elas não ofertaram um espaço de acolhimento das suas expectativas e sentimentos relacionados a este fator de risco psicoemocional. Bispo e Bispo (2010) asseguram que "o aleitamento materno além dos seus aspectos biológicos ligados a nutrição e a saúde do recém-nato, possui também aspectos psíquicos, subjetivos e emocionais a serem observados nas mães interditadas de amamentar, já que esta poderá trazer consequências psicológicas" (p. 4).

Sem dúvida, esse olhar imbuído de um conhecimento científico natural, reveste-se de um cuidado que se encontra no campo do ôntico. Mas, como pensar o cuidado, um acompanhar o outro olhando para a trama de sentido que se constitui entre os entes que vêm ao encontro do homem no mundo? Pensamos que acompanhar pela via do cuidado como pré-ocupação possibilita um recolher do pedido das pacientes, abrindo-se para junto com elas, compreender a demanda desvelada na trama de sentido constituída na coexistência de ser-no-mundo-com-outros. Será que apenas um cuidado por ocupação, revelado pela via da informação/conhecimento, dá conta dos medos/temores já anunciados neste estudo? É sabido que, segundo Heidegger (1927/2002), o ser-aí se encontra lançado a estados de humores/ânimos, por meio dos quais se inclina a fugir, uma vez que tem de suportar o peso de sua existência. O homem teme, pois é ele mesmo afetado, já que o medo se volta para quem teme e não para o que teme. Assim, em meio às ocupações do cotidiano, deparamo-nos com um certo tédio e não sabemos diante de que nos angustiamos. Começamos a procurar cada vez mais o contato com os entes e as coisas ao nosso redor, e assim, nos ocuparmos na busca de sair desse estranho emaranhado em que nos encontramos e, com isso, mergulhamos cada vez mais na angústia.

Compreendemos, assim que apenas as informações técnicas sobre a amamentação ou qualquer outro aspecto próprio de uma gestação, em especial a gestação de mulheres transplantadas renais, e seus prováveis benefícios ou malefícios, considerando a IRC e seu tratamento, não foram suficientes para cuidar das gestantes diante dos desejos e sentimentos que as fragilizavam existencialmente:

Maria Eduarda - Quando eu soube que não ia amamentar... fiquei triste! Essa experiência de amamentação eu não tenho! Relatam que você fica mais próxima do bebê... eu acredito que sim! Porque eu não amamentei... eu acho que a gente perde um pouco do laço! Eu sinto muito não ter amamentado (silêncio)! [...] Era como se eu tivesse que afastar a minha cria de mim e com isso você não se sente bem! Eu sentia como se tivesse fazendo uma maldade com ela! Mesmo sabendo que não podia dar o meu leite! Quando eu ia tomar banho... derramava muito leite... e eu pensava... "meu Deus... eu nem posso dar a minha filha... nem posso doar... tenho que jogar fora! Essa é a parte que eu acho mais difícil!

Eliana - Eu queria muito!... Não pode amamentar por causa do medicamento que a gente toma!

Notoriamente, o viver nos coloca inusitadamente no campo experiencial, do conhecido ao desconhecido, do abrigo ao desabrigo. Vale dizer, na solicitação de elaboração de uma vivência de algo novo, inusitado, sem experiências anteriores que possam servir de referência, como por exemplo, como lidar com a amamentação por encontrar-se na situação de ser uma mulher transplantada renal. Deparar-se com a falta, com o que não “está à mão”, com 
o aparecimento a impertinência, deixa a narradora-colaboradora paralisada sem saber o que fazer nos remetendo a Heidegger (1927/2002), ao afirmar que "Ficar sem saber o que fazer é um modo deficiente de ocupação, que descobre o ser simplesmente dado de um manual” (p. 116). Encontrar-se diante do que "não está no manual” perturba, obstruindo o caminho para a ocupação e lançando-nos ao encontro da estranheza, do não se sentir em casa, da inospitalidade do mundo, da angústia. Nessa direção, de acordo com o referido autor, a angústia não é compreendida como sintoma ou patologia, mas uma condição do existir humano. Boss (1981) ressalta que, “[...] não é a cabeça, e o intelecto dos nossos pacientes, mas seu coração que está trancado e estrangulado pela angústia.” (p. 42). Mergulhada nas solicitações e envolta aos afazeres de uma puérpera, estaria Maria Eduarda, tentando evitar o desabrigo da angústia? Em sendo assim, ao aproximar-se do desconhecido familiar, da inospitalidade, abre-se para avizinhar-se de si, bem como de suas possibilidades mais próprias.

Por outro lado, vemos, também, que durante a gravidez, a questão da amamentação deve ser posta e tratada de forma atenciosa e responsável pela equipe de saúde, pois é nesse período que a mulher começa a entrar em contato com a impossibilidade de amamentar e precisa ser orientada para enfrentar essa situação durante a gestação e após o parto:

Maria Eduarda - Enquanto ela estava na minha barriga... eu não pensei em como seria depois que ela nascesse! A gente acha que é fácil... "não... você não pode dar de mamar... você vai enfaixar o peito... você vai desprezar o leite!” A gente acha que assimila... mas na hora que põe a criança no braço e vê que ela tá procurando... você sabe que ela tá sentindo que o peito está ali e o leite... e eu não posso dar! Na gestação eu não imaginava que ia ser difícil assim!

Eliana - Ao chegar em casa... foi aquela coisa, só alegria! Só coisa boa, só alegria. Aí eu não posso amamentar [...] Eu queria muito, mas eu já sabia que não podia. Não era só eu, eram todas as transplantadas.

No trânsito por entre pré-gestação, gestação e pós-parto, surge a questão da espacialidade e da temporalidade. Ambas se impõem como constituintes da condição humana. Importa esclarecer que, para Heidegger (1927/2002), a espacialidade afastando-se da ideia de um local fixo, concreto, sendo vista como um modo do homem existir no mundo com-outros, como ele se situa em sua existência; já a temporalidade longe da ideia de períodos demarcados pelo presente, passado e futuro, revela que o ser humano pode compreender a sua própria história, pode modificá-la e, por isso pode ser visto como ser temporal e histórico. Nessa perspectiva, "Somente quando nossa existência puder ser articulada numa história e tivermos testemunhas para ela, o sentido que fazemos na vida se desencobrirá" (Critelli, 2012, p. 69-70).

Ambas as narradoras-colaboradoras referem-se saber, anteriormente, da impossibilidade de amamentar. Sabemos que, ao longo do processo de adoecimento causado pela IRC, o doente renal crônico e sua família conhecem diversas perdas, como a perda de uma maior autonomia e liberdade, muitas vezes da autoestima, perdas econômicas, e também as limitações hídricas e alimentares, etc. Entretanto, pela via da temporalidade, surge a demanda de ter que se apropriar dessa situação como uma remissão as suas historicidades, como modo de localizarem-se e encontrarem-se a partir de um contexto situacional, abrindo possibilidade para elaborar experiência. Desse modo, "historicizar-se não é simples narração de fatos sequenciais, mas a elaboração da experiência de existir, lançando-me ao mesmo tempo em que sou lançado" (Santos, 2005, p. 139).

A impossibilidade de amamentar, mesmo que sabidamente conhecida, parece ser sentida como mais uma perda e surge imbricada com o inesperado de surpreender-se com a ausência da amamentação. O tempo cronológico sinaliza que já é hora de amamentar. No entanto, a situação de ser uma mulher transplantada renal dá existência ao aspecto existencial constituinte da condição humana, o cuidar de ser, embora na experiência das narradoras-colaboradoras, a impossibilidade de amamentar aumente a vivência dessas perdas e se desdobre em outros modos de lidar com esse acontecimento:

Maria Eduarda - Ela foi criada até os dez anos sabendo que mamou! Sabe por que eu não disse antes? Porque como todos meus sobrinhos mamaram... Eu achei melhor não contar... pra ela não colocar na cabeça... "eles mamaram e eu não mamei”! Eu espero que ela tenha uma experiência normal! A minha experiência não foi normal por causa da minha situação... da minha saúde!

Na história de Maria Eduarda, a privação do aleitamento materno manteve-se escondida da filha até pouco tempo atrás, por ter sido vivenciada por ela como uma experiência de sofrimento e ameaçadora de sofrimento para sua filha. Se de um lado, poderíamos compreender essa sua atitude como uma "enganação/negação" ao outro de aspectos próprios de sua história, de outro, podemos compreender ao pensar o outro como coexistente, como coparticipante do ser-no-mundo que, “[...] os outros são encontrados emergindo do mundo no qual o ser-o-aí habita referindo-se a ele através do cuidado" (Heidegger, 1981, p. 35), mesmo que esse cuidado seja experienciado como um cuidado descuidado. Como diria Duarte (2013, p. 69), "Não se trata propriamente de amor, mas de acolhimento amistoso [...]. Heidegger nos mostra que, no resguardo de nossa precariedade constitutiva, o cuidado de si é também um cuidado do outro.”. 
As narrativas de Maria Eduarda e de Eliana nos fazem pensar que diante das surpresas de uma gestação em mulheres transplantadas renais vivenciam, chegando até a pensar numa "não normalidade", a mulher transplantada renal traz consigo uma forte demanda de escuta, desde o diagnóstico da IRC até o transplante. Durante a gestação, essa demanda pode se acentuar, visto que a gravidez é um período onde a mulher e sua família passam por diversas tensões, permeadas por mudanças não apenas fisiológicas, mas também psicossociais provocando mudança e novas composições de papéis sociais, (Maldonado, 2002), e acrescentamos as mudanças existenciais, bem como outros modos de ser-no-mundo. Na narrativa de Maria Eduarda, podemos encontrar algumas perguntas que sinalizavam a mudança que estava acontecendo em sua vida e, junto com as mudanças as inquietações que devem ser consideradas com atenção, serenidade e cuidado:

Maria Eduarda - [...] depois que ela nascer... como é que eu vou fazer? Porque você tem que elaborar toda a sua vida novamente! Dá um sentimento de medo... de insegurança... Como enfrentar... depois que ela nascer? Você pensa... "quem vai tomar conta? Como eu vou trabalhar?” Por eu ser transplantada... como é que ia ser a minha vida? Assim... é... um turbilhão de sentimentos!!

Diante dessas questões, pensamos que elas podem aparecer como uma maneira de sustentar a angústia do ser lançado, como uma possibilidade de manter a "esperança” da existência frente à fugacidade liquidificante do mundo contemporâneo, e aqui, especificamente frente à fugacidade do próprio existir. Por esse prisma, a narradora-colaboradora revela que a experiência da gestação pode ser vivida como um sinal de desamparo diante da transitoriedade do próprio existir, da inospitalidade do mundo, mantendo-a acuada para dar conta do seu acontecer humano. Barreto (2006) assinala que a angústia, "Diz respeito a entregar-se à responsabilidade de ser: de acolher o modo de ser propriamente ou impropriamente" (p. 12), o que converge com a ideia que a angústia se manifesta no lançamento do ser-projeto (Heidegger, 1927/2002).

A angústia revelada pelo "não saber", pela ausência de controle do que está acontecendo e do que pode acontecer vai aparecendo como acontecimento disruptor para que a narradora-colaboradora ponha seus temores em questão. Estaria aqui uma abertura para refletirmos sobre a possibilidade de uma escuta psicológica à gestante e a sua família? Para Caldas et al. (2013), as intercorrências durante a gravidez fragilizam a mulher e a sua família, levando-as, muitas vezes, a um sofrimento psíquico. Freitas e Cosmo (2010) argumentam que o trabalho do psicólogo ao lado das pessoas que são afetadas pela IRC é necessário "para garantir um atendimento mais humanizado, que reconheça a singularidade de cada paciente [...] e que faça emergir dentro dos recursos pessoais a capacidade de ressignificação da própria vida” (p. 31). Nas instituições de saúde - espaço social favorável ao compartilhar das experiências singulares e coletivas - o sofrimento psíquico está sempre presente e o que está em questão é a possibilidade da vida. Nesse espaço, o lugar do psicólogo deve está posto enquanto profissional que possibilita a narrativa para que o cuidar de si, apropriando-se de seus próprios caminhos, possa ser acompanhado. Logo, “[...] a clínica como cuidado remete aos modos possíveis de cuidar num determinado tempo e numa determinada situação." (Barreto, 2008, p. 5).

Entretanto, indagamos: há um reconhecimento da importância do trabalho do psicólogo junto às mulheres gestantes pós-transplantadas renais?

Maria Eduarda - O medo foi durante a gravidez toda! Não tive acompanhamento de psicóloga... até porque eu acho que o médico achou que não era necessário!

Esse depoimento nos impõe outra questão: quem diz da necessidade de uma escuta psicológica? Quem deve expressar a pró-cura? Pensar na atitude de pró-cura nos remete a origem latina da palavra cura, como cuidar. Sob esse aceno, "a atitude clínica como pró-cura é, por extensão, possibilidade de ações tanto para o cuidado, quanto para o modo como se experiencia esse processo de pró-cura.” (Santos, 2005, p. 89). Nessa direção, "o pôr-se diante do outro não suprimiria nem supriria suas ocupações e necessidades, mas cuidaria do outro ao restituir-lhe ao próprio cuidado de si” (Duarte, 2013, p. 67).

Por outro lado, outro aspecto merece nossa atenção, e outra inquietação aparece: o cuidado psicológico muitas vezes negligenciado, fere o princípio bioético da beneficência? O princípio da beneficência deve ser prioridade para a promoção da saúde. Esse princípio dá ênfase ao cuidado disponibilizado pela equipe de saúde. Existe um consenso dos profissionais da saúde de que o bem deve ser feito para garantir o cuidado humanizado, porém existem dificuldades em definir o que realmente deve ser considerado um bem para o paciente e quais decisões e encaminhamentos devem ser feitos para garantir saúde através do cuidado integral. Segundo Martin (2004):

A beneficência precisa olhar para o que é de interesse do doente não apenas no nível físico, mas também nos níveis mental, social e espiritual. As angústias, os medos, a solidão do doente também são fatores a pesar. Nesta perspectiva, é importante tratar não apenas a doença, mas também a pessoa que está doente, e a beneficência é o conjunto de todos os fatores que levam ao bem-estar do ser humano. (p. 42)

Uma vez compreendido que existem riscos psicoemocionais e sentimentos que fragilizam a mulher pós-trans- 
plantada renal na sua experiência da gestação e sendo a beneficência um princípio bioético norteador da praxis, a oferta dos cuidados psicológicos se faz necessária, visando "o bem" em prol da mulher transplantada gestante, e que, desta forma, o cuidado possa ser experienciado.

\section{Considerações finais}

Ao longo do trabalho foi possível perceber que a gestação vivida após transplante renal é singular e única, uma vez que ela se tece partindo da história de vida de cada mulher, do seu modo de enfrentamento do processo saúde-doença, do sentido que dão à sua experiência e ao seu caminhar. Essa gestação também é plural, pois cada mulher a vivencia com os vários "outros" que são no mundo com ela: família, cultura, sociedade, etc. Nas narrativas de Eliana e Maria Eduarda, foi revelado que o modo delas de "ser-cuidado" mostrou-se na maneira como enfrentaram o fenômeno da gestação e IRC. Esse cuidado orientou suas atitudes e decisões, em busca de um maior bem-estar para elas e suas famílias. O cuidado de si e do outro permeou todos os acontecimentos numa pró-cura - para cuidar de existir no mundo-com-outros.

As colaboradoras-narradoras expressaram em seus depoimentos o sentimento de medo, experienciado por elas ou pela família durante toda a gestação. O medo era referente às possibilidades de perdas, como por exemplo, a perda do próprio enxerto, ou os riscos para o bebê e para a gestante, que a gestação considerada de alto risco representa. Esse medo foi norteador de algumas escolhas durante e após o período gravídico, tais como: a decisão pela laqueadura de trompas ou a escolha de viver os primeiros meses da gestação de forma mais reservada, sem contar para a família da espera do segundo filho. O medo presente na família, referido pela narradora-colaboradora, foi intensificado pela falta de informação em relação à gravidez associada ao transplante renal e ao pouco acolhimento que seus familiares tiveram para expressar seus sentimentos e dúvidas.

A experienciação desses medos remete-nos a Boss (1981) ao apontar que a angústia nos coloca diante de questões eminentemente singulares, cujo modo de manifestação expressa uma compreensão de sentido: “[...] cada angústia humana tem um 'de que', do qual ela tem medo e um 'pelo que' pelo qual ela teme” (p. 26, aspas do autor). Ontologicamente, a angústia como fenômeno existencial, é vista como condição humana, se manifestando onticamente pelo medo/temor que "[...] vela, ao mesmo tempo, o estar e ser-em perigo na medida em que deixa ver o perigo a ponto da pre-sença precisar se recompor depois que ele passa” (Heidegger, 1927/2002, p. 196).

Emaranhada na angústia diante do risco eminente do morrer, as narradoras-colaboradoras deparam-se com essa possibilidade irrevogável da sua existência - a sua própria finitude. Como diz Bruns e Trindade (2001),
Em sua vida diária, o Dasein vive de tal forma mergulhado no mundo que pouco pensa acerca de sua existência, do modo como a vive. A morte é vista, fugazmente, como o final de sua vida, o que o amedronta, pois é vista como um impedimento para tudo o que ele almeja fazer. (p. 74)

Esta pesquisa apontou, por fim, para uma importante demanda para a Psicologia, vinda tanto da gestante quanto da sua família. O psicólogo é convocado a inclinar-se sobre a experiência do fenômeno da gestação após transplante renal, que se encontra permeada pelo sofrimento psíquico. Há de estar atento aos modos como o homem se mostra assumindo a "ética do cuidado", que segundo Santos (2013), "tem a ver com a 'preocupação' e a responsabilidade que temos em relação ao cuidado com o outro” (p. 102, aspas do autor). O psicólogo pode contribuir com os cuidados à mulher transplantada renal gestante e sua família debruçando-se em direção a essa mulher e sua família para escutá-las na experiência do sofrimento. A oferta da atenção psicológica faz parte da construção de uma prática norteada pelo princípio bioético da beneficência e é essencial para a promoção da qualidade de vida das mulheres com IRC em processo da gestação. Nesse contexto, o psicólogo, abordará questões que, muitas vezes, são evitados pela equipe e que, se não recolhidas e cuidadas podem intensificar o sofrimento psíquico.

As possibilidades compreensivas trazidas neste estudo não foram esgotadas, elas são apenas o início de uma leitura que pode ser ampliada com novas pesquisas. Ainda há muito a ser pensado e discutido acerca do complexo fenômeno da gestação após transplante renal.

\section{Referências}

Almeida, F. M. (2005). Ser clínico como educador: uma leitura fenomenológica existencial de algumas temáticas na prática de profissionais de saúde e educação. Tese de Doutorado em Psicologia Escolar e Desenvolvimento Humano. Instituto de Psicologia, Universidade de São Paulo, São Paulo.

ABTO, Associação Brasileira de Transplante de Orgãos (2014a). Registro Brasileiro de Transplante. Ano XX, n. 3. Recuperado em 30 janeiro de 2015, de: <http://www.abto.org.br/abtov03/ Upload/file/RBT/2014/rbt3-trim-parc.pdf>.

ABTO, Associação Brasileira de Transplante de Orgãos (2014b). Manual de Transplante Renal. Recuperado em 30 janeiro de 2015, de: <http://www.abto.org.br/abtov03/Upload/file/ manual_do_transplantado/manual_transplante_rim.pdf $>$.

Barreto, C. L. B. T. (2006). Ação clínica e os pressupostos fenomenológicos existenciais. Tese de Doutorado de Psicologia. Universidade de São Paulo, São Paulo.

Barreto, C. L. B. T. (2008). Uma possível compreensão fenomenológica existencial da clínica psicológica. In: VIII Simpósio Nacional de Práticas Psicológicas em Instituições - Atenção Psicológica: Experiência, Intervenção e Pesquisa, v. 8. p. 1-14, São Paulo: USP. 
Bispo, T. M. S. \& Bispo, M. R. G. (2010). Os aspectos psicológicos da interdição à amamentação, 25p. Disponível em: < http:// www.psicologia.pt/artigos/textos/TL0163.pdf>.

Bohachick, P. et al. (1992). Psychosocial outcome six months after Heart Transplant Surgery: a preliminary report. Research in Nursing \& Health, 15, 165-173.

Boss, M. (1981). Angústia, culpa e libertação: ensaios de psicanálise existencial. 3. ed. São Paulo: Duas Cidades.

Brasil. (1990a). Lei $n^{0}$ 8.080, de 19 de setembro de 1990. Recuperado de <http://www.planalto.gov.br/ccivil_03/leis/ l8080.htm $>$.

Brasil (1990b), Lei $n^{o} 8.142$, de 28 de dezembro de 1990. Recuperado de <http://www.planalto.gov.br/ccivil_03/leis/ 18142.htm>.

Brasil (1997), Lei no 9.434, de 04 de fevereiro de 1997. Recuperado de <http://www.planalto.gov.br/ccivil_03/leis/19434. htm>.

Brasil (2001). Lei no 10211, de 23 de março de 2011. Recuperado de < http://www.planalto.gov.br/ccivil_03/leis/LEIS_2001/ L10211.htm $>$.

Brasil (2012). Gestação de Alto Risco: manual técnico. Brasília: Ministério da Saúde. Secretaria de Atenção a Saúde. Recuperado de < http://www.pesquisa.bvsalud.org/bvsms/resour$\mathrm{ce} / \mathrm{pt} / \mathrm{mis}-34503>$.

Bruns, M. A. T. \& Trindade, E. (2001). Metodologia fenomenológica: a contribuição da ontologia-hermenêutica de Martin Heidegger. In: M. A. T. Bruns \& A.F. Holanda (Orgs). Psicologia e pesquisa fenomenológica: reflexões e perspectivas (p. 67-82). São Paulo: Omega Editora.

Bruscato, W. L. (2004). A prática da psicologia hospitalar na Santa Casa de São Paulo: novas páginas em uma antiga história. São Paulo: Casa do Psicólogo.

Caldas, D. B., Silva, A. L. R., Boing, E., Crepaldi, M. A. \& Custódio, Z. A. de O. (2013). Atendimento psicológico no pré-natal de alto risco: a construção de um serviço. Psicologia Hospitalar, 11 (1), 66-87.

Critelli, D. M. (2006). Analítica do Sentido: uma aproximação e interpretação do real de orientação fenomenológica. São Paulo: Brasiliense.

Critelli, M. D. (2012). História pessoal e sentido da vida: historiobiografia. São Paulo: EDUC: FAPESP.

Duarte, A. (2013). Ser e tempo como ética do cuidado: finitude e responsabilidade existencial. In: Z. Lopacic (Org.). Winnicott e a ética do cuidado (p. 57-69). São Paulo: DWW Editorial.

Freitas, P. P. W. \& Cosmo, M. (2010). Atuação do Psicólogo em Hemodiálise. Revista da SBPH, 13 (1), 19-32.

Heidegger, M. (2002). Ser e tempo: parte I. 12 ed. Petrópolis, RJ: Vozes (Original de 1927).

Heidegger, M. (1981). Todos nós... ninguém: um enfoque fenomenológico. São Paulo: Editora Moraes.
Loparic, Z. (2013). A ética da lei e a ética do cuidado. In: Z. Lopacic (Org.). Winnicott e a ética do cuidado (p. 19-53). São Paulo: DWW Editorial.

Loparic, Z. (1995). Ética e finitude. São Paulo: EDUC.

Maldonado, M. T. P. (2002). Psicologia da gravidez: parto e puerpério. 16. ed. São Paulo: Saraiva.

Martin, L. M. (2004). A ética e a humanização hospitalar. In L. Pessini \& L. Bertachini (Orgs.). Humanização e cuidados paliativos (p. 31-50). São Paulo: Loyola.

Medina-Pestana, J. O., Galante, N. Z., Tedesco-Silva Jr., H., Harada, K. M., Garcia, V. D., Abbud-Filho, M., Campos, H. H. \& Sabbaga, E. (2011). O contexto do transplante renal no Brasil e sua disparidade geográfica. Jornal Brasileiro de Nefrologia, 33 (4), 472-484.

Minayo, M. C. S. (Org.). (2002). Pesquisa social: teoria, método e criatividade. Petrópolis: Vozes.

OMS, Organização Mundial da Saúde (2014). Compartilhando Responsabilidades na Promoção da Justiça. Recuperado de <http://sinus.org.br/2014/wp-content/uploads/2013/11/ OMS-Guia-Online.pdf $>$.

Panaye, M., Jolivot, A., Lemoine, S., Guebre-Egziabher, F., Doret, M., Morelon, E. \& Juillard, L. (2014). Grossesse en insuffisance rénale terminale: épidémiologie, prise en charge et pronostic. Néphrologie et Thérapeutique, 10 (7), 485-491. https://doi.org/10.1016/j.nephro.2014.06.006

Potes, M. del P. E., Pelaez, Z. R. F. \& Escobar, J. A. D. (2011). El autocuidado: un compromiso de la formación integral en educación superior. Hacia Promoc. Salud, 16 (2), 132-146.

Quérin, S., Clermont, M. J., Dupre-Goudable, C. \& Dalmon, P. (2011). La communication médecin-malade en néphrologie. Néphrologie et Thérapeutique, 7 (4), 201-206.

Quintas, J. (2013). Nos corredores de um hospital: a experiência de ser psicóloga numa instituição pública de saúde. Recife: Autor.

Ribeiro, R. G. T. (2010). Análise dos resultados maternos e perinatais das gestantes transplantadas renais. Dissertação de Mestrado em Obstetrícia e Ginecologia. Faculdade de Medicina, Universidade de São Paulo, São Paulo.

Rodrigues, J. T. (2006). Terror, medo, pânico: manifestações da angústia no contemporâneo. Rio de Janeiro: 7Letras.

Rossi, A. C., Deus, R. B. de \& Figueiredo, F. M. G (2011). Transtornos Mentais Associados aos Pacientes com Insuficiência Renal Crônica. In: W. Malagutti \& R. R. N., Ferraz (Orgs). Nefrologia: uma abordagem multidisciplinar (p. 1-54). Rio de Janeiro: Rubio.

Santos, E. S. (2013a). Em busca de uma ética do cuidado à luz de Heidegger, Nishitani e Winnicot. In: Z. Lopacic (Org.). Winnicott e a ética do cuidado (p. 101-113). São Paulo: DWW Editorial.

Santos, S. E. de B. (2005). A experiência de ser ex-esposa: uma oficina sociopsicodramática como intervenção para problematizar a ação clínica. Dissertação de Mestrado em Psicologia Clínica. Universidade Católica de Pernambuco: Recife. 
Santos, S. E. de B. (2016). “Olha!... Arru(A)ção!?...” A Ação Clínica no Viver Cotidiano: Conversação com a Fenomenologia Existencial. Tese de Doutorado em Psicologia Clínica. Universidade Católica de Pernambuco: Recife.

Sesso, R. C. C., Lopes, A. A., Thomé, F. S., Lugon, J. R., Watanabe, Y. \& Santos, D. R. (2012). Diálise Crônica no Brasil - Relatório do Censo Brasileiro de Diálise, 2011. Jornal Brasileiro de Nefrologia, 34 (3), 272-277. Recuperado de <http://www.scielo.br/scielo.php?script=sci arttext\&pid =S01012800201200 0300009 \&lng=en \&tlng=pt. 10.5935/0101-2800.20120009>.

Silva, A. C. B., Cardoso, P. M. R., Sá, R. A., Kruger, S. J. N. \& Oliveira, C. A. (2014). Transplante Renal e Gestação. Femina, 42 (2), 113-118.

Tavares, A. P. S. (2011). Cuidados paliativos na doença renal crônica. In: F. S., Santos (Ed.), Cuidados paliativos: diretrizes, humanização e alívio de sintomas (p. 507-515). São Paulo: Atheneu.

Thiollent, M. (1986). Metodologia da Pesquisa-ação. São Paulo: Cortez.

Ravagnani, L. M. B., Domingos, N. A. M. \& Miyazaki, M. C. O. S. (2007). Qualidade de vida e estratégias de enfrentamento em pacientes submetidos a transplante renal. Estudos de Psicologia, 12 (2), 177-184.

Viviane Rodrigues de Figueredo Azevedo Amaral - Psicóloga, com Mestrado em Psicologia Clínica pela Universidade Católica de Pernambuco; Psicóloga especialista na área da saúde pelo Hospital das Clínicas - UFPE. Membro da Société Francophone de Néphrologie Dialyse et Transplantation, Membro do Instituto de Bioética e Biodireito de Pernambuco. Psicóloga na Clínica de Diálise do Cabo. Email: rfviviane@gmail.com

Telma Costa de Avelar - Possui Graduação em Psicologia pela Universidade Federal de Pernambuco e Mestrado em Psicologia Cognitiva pela Universidade Federal de Pernambuco; Professora Assistente da Universidade Federal de Pernambuco e Tutora no Programa de Residência Multiprofissional em Saúde do Hospital das Clínicas da Universidade Federal de Pernambuco. Email: avelar.telma@gmail.com

Suely Emilia de Barros Santos - Psicóloga. Doutora em Psicologia Clínica pela Universidade Católica de Pernambuco (UNICAP). Professora Adjunta da Universidade de Pernambuco (UPE). Coordenadora da Residência Multiprofissional em Saúde Mental com Ênfase no Cuidado do Usuário e da Família. Membro externo do Comitê Científico de Iniciação à Pesquisa (CCIP) da UNICAP. Email: suely.emilia@upe.br

Recebido em 04.04.2015

Primeira Decisão Editorial em 07.03.2016

Aceito em 22.05.2017 